\title{
Moderating Effect of Hofstede's Cultural Values on the Locus of Control/Job Performance Relationship of Managers in USA, Mexico, South Korea and Hong Kong
}

\author{
Maria A. Leach-López \\ Auburn University Montgomery • Montgomery, Alabama
}

\section{Abstract}

This study evaluates relationships between job performance, locus of control, and cultural values. Survey data was collected from 265 managers working for US controlled firms located in the US, Hong Kong, South Korea and Mexico. Findings indicate that there is a stronger relationship between reported job performance and a manager's personality versus the manager's culture. These results should help multinational firms better understand a significant influence on the job performance of mid-level managers working in different countries. US controlled, manufacturing multinational firms can feel confident when designing management control systems at the individual level regardless of the country in which they operate.

\section{Introduction}

Today's global economy poses many challenges for multinational corporations (MNCs). Cross-national human resource management is one of many logistic challenges that MNCs must address. Human resource management requires a significant investment in time and money and it is important for international companies to identify and attract high performance managers. Another challenge for MNCs is whether to design management control systems for each country in which they operate at a macro level for the whole company (where a Human Resource Management policy is developed for the whole organization and is directed from headquarters) or at a micro level for individual employees in the company within a specific country (where each subsidiary and plant would develop its own HRM policy without a centralized model). In other words, should the management control systems be directed from the multinational's headquarters, or should management control systems be designed for each country considering that country's culture? It is useful to know what is more significant when attempting to maximize job performance: a manager's personality or a manager's culture. Barrick and Mount (2005) concluded that personality is an effective predictor of job performance and emphasized that managers should care about the personality of employees. But MNCs have employ- 
ees located in various and diverse cultures. Competitive success in a global environment requires an awareness of how personality and culture may affect employees' job performance. There are practical implications to finding whether MNCs must consider the personality or the cultural values of the manager when job performance is to be maximized.

In a meta-analysis study, $\mathrm{Ng}$, Sorensen and Eby (2006) examined the relationship of the personality variable locus of control (LOC) and various work outcomes and found that internal locus of control was positively associated with favorable work outcomes. Spector (1982) found that internals have higher job performance than do externals. The role of personality at work has received increased attention (Barrick \& Mount, 2005) because all managers have a personality and personality helps predict and explain behavior at work (Goldberg, 1993).

In addition to managers' personalities, MNCs must remember that national culture must be considered when managerial practices are implemented. There are various management control systems (MCSs). A universally used MCS is Budgeting. According to Leach-López et al. (2007) the managerial practice of budget participation works to help job performance of managers in various countries. But is job performance affected by the personality or by the culture of the manager? Should a different MCS be designed for each country? National culture is an important field of study in various business disciplines: Leach-López, Stammerjohan, and McNair (2007) and Lagrosen (2002), among many others, found that culture matters.

Flynn and Saladin (2006) believe that the role of national culture has not been systematically investigated in an organizational context. Kirkman, Lowe and Gibson (2006) also believe that there are still many gaps in cultural studies and suggest various research ideas that still need to be explored. This study tries to narrow this gap as a first line of research. It is hoped that other researchers will replicate and expand the results obtained and presented below.

The research presented in this paper investigates the moderating effect of cultural values on the job performance/locus of control relationship. The results obtained should help MNCs understand job performance in an international setting.

\section{Model Variables}

\section{Job Performance}

Personality as a predictor of job performance has been widely studied in the past decades. As far back as 1965, Guion and Gottier (1965) concluded that personality was not a valid predictor of job performance. Since then, many researchers 
have challenged this conclusion. Hogan (2005) published a historical review of this line of research which continues to this day. Following this line of inquiry led Penney, David and Witt (2011) to conclude that "personality is an important determinant of individual behavior in the workplace (p.297)."

Campbell, McCloy, Oppler, and Sager (1993) describe job performance as actions that are under an individual's control, and which help reach the organization's goals. Campbell, McHenry, and Wise (1990) and Campbell et al. (1993) have introduced various models that attempt to increase our understanding of job performance. These models have served as an impetus for further theoretical and empirical development of this construct.

Leach-López, Stammerjohan, and Rigsby (2008) studied the moderating effect of personality and culture in the relationship between budget participation and job performance. They tested this relationship using a separate model for each sample used: US managers and Mexican managers. They detected a significant relationship between budget participation and job performance for each of the samples used in their study. They did not find that personality moderated these relationships. Thus they conclude that culture does matter in the budget participation-job performance relationship and suggested that MNCs should be cautious when using and transferring MCSs from the US to Mexico. Leach-López et al. (2008) reached their conclusion without testing the cultural values of the respondents.

\section{Locus of Control}

Locus of Control (LOC) is a personality construct denoting an individual's generalized expectancies for control of reinforcements. Rotter (1966) described LOC as distributing individuals according to the degree to which they accept personal responsibility for what happens to them. Under LOC, individuals are classified as being either more internal or more external oriented. Responses to Rotter's (1966) questionnaire provides a LOC value for each respondent where higher LOC calculated values indicate a more external orientation and lower LOC calculated values indicate a more internal orientation. Individuals who believe they can control reinforcements in their lives are considered to be more internal. Those who believe that fate, luck, or other people control reinforcements in their lives are considered to be more external (Spector, 2005). Rotter (1966) found that personalities that tend to be external are generally more susceptible and submissive to direct influence by others. Personalities that tend to be more internal are not as susceptible and submissive to others' influence. 
According to Bruk-Lee, Khoury, Nixon, Goh and Spector (2009), locus of control is one of the most studied personality traits and its effect on work outcomes has been reported widely (e.g., Judge \& Bono, 2001; Ng et al., 2006; Spector, 1982). Broad dimensions of personality, such as the Big Five are not good predictors of job performance (Murphy \& Dzieweczynski, 2005). Barrick, Mount \& Judge (2001) found that measures of the Big Five factors have little to do with performance so that "correlations between measures of the Big Five personality dimensions and measures of job performance are generally quite close to zero" (Murphy \& Dzieweczynski, 2005, p. 345). Given the reliable relationship between Locus of Control and job performance and the problems associated with the Big Five factors, a broad measure of personality, Rotter's (1966) Locus of Control measurement was used in this study.

\section{Hofstede's Cultural Values}

Culture is an important construct in that it indicates how, in general, a person should behave in a particular role or status in a given society (Harrison, 1993). The concept of culture used by most researchers is based on the work of Hofstede (1980), who developed a commonly acceptable, well-defined, and empirically-based terminology to identify and describe cultural values. Hofstede (1980) and Hofstede and Bond (1988) identified five dimensions of culture: large versus small power distance, individualism versus collectivism, masculinity versus femininity, strong versus weak uncertainty avoidance, and long-term orientation versus short-term orientation.

Power distance. Power distance (PDI) refers to the way in which individuals handle the problem of human inequality. A large PDI classification would be characterized by the acceptance of inequality; individuals would tend to accept a hierarchical order in which everybody has a place which needs no further justification (Perera $\&$ Mathews, 1990). A small PDI would require justification of power inequalities that do exist; thus, individuals with small PDI require that inequality in relationships between supervisors and subordinates should be minimized. Small PDI values indicate that subordinates and supervisors regard each other as equivalent people who should have equal rights (Hofstede, 1980, 2001).

Individualism. Individualism (IDV) measures how individuals look after their own self-interests and the interests of their immediate family only. At the other extreme of this dimension is collectivism where everyone is expected to look after the interest of their relatives or other members of their own in-group (Hofstede, 1983b). 
A high individualism score indicates that people focus on themselves as individuals rather than on the groups to which they may belong. Under this perspective, an individual is seen as having an identity not dependent upon a group affiliation (Hofstede, 1980, 2001).

Uncertainty avoidance. Uncertainty avoidance (UAI) relates to the degree to which individuals feel uncomfortable with uncertainty and ambiguity. With strong UAI there is low tolerance for ambiguity and uncertainty and an aversion towards risk taking (Hofstede, 1980, 2001), which means that people prefer group decisions, consultative management, and believe that subordinates should not be able to influence superiors' decisions. According to Perera and Mathews (1990), the fundamental issue involved in this dimension is how individuals react to the fact that the future is not known. Strong uncertainty avoidance individuals would like to beat an unpredictable future which creates a higher level of anxiety.

Masculinity. Masculinity (MAS) represents a societal preference for showing off, achievement, heroism, assertiveness, making money or enjoying material success. At the other extreme is Femininity which represents a preference for putting relationships with people before money, helping others, caring for the weaker, the quality of life, preserving the environment. The MAS value describes the extent to which aggressiveness and success are valued instead of concern for relationships (Hofstede, 1980, 2001). This dimension draws attention to the existence of competitiveness as opposed to solidarity, equity as opposed to equality, and achievement motivation as opposed to relationship motivation.

Long-term orientation. Long-term orientation (LTO) refers to a cultural value fostering virtues oriented towards future rewards. Short-term orientation stands for a cultural value fostering virtues related to the past and the present, in particular respect for tradition, preservation of "face," and fulfilling social obligations (Hofstede, 1980, 2001). With a long term orientation there is a tendency towards valuing order in relationships by status and observing this order. With a short term orientation there is a tendency towards valuing personal steadiness and stability, thus discouraging change or risk. This cultural dimension was originally labeled Confucianism, but it was renamed since both opposing poles of the dimension contain Confucian values (Hofstede, 2001, p. 355).

\section{Expected Results}

According to Ozer (2008), people who are more internal oriented take more assertive actions to change the work environment or to change jobs when they are 
not satisfied, thus will likely perform better (Blau, 1987; Judge \& Bono, 2001; Ng et al., 2006). For this study, LOC was measured so that the larger the value, the more external is the manager. The lower LOC values indicate a more internal personality. Job performance is measured so that the higher values indicate higher job performance. The findings should indicate an inverse relationship between LOC and performance, i.e. internals should report higher performance.

\section{LOC and Cultural Values}

Hofstede (2001) explains that culture and personality interact so that "cultural traits can sometimes be measured through personality tests" (p. 10). Thus, correlations between LOC and Hofstede's cultural values would be expected. The more internal managers would feel in control of their destiny and have lower LOC values. They would be expected to exhibit high individualism (IDV), high masculinity (MAS), low power distance (PDI), low uncertainty avoidance (UAI), and to have a short term orientation. Lower PDI managers would be more assured of their position in the firm, and those with lower UAI can tolerate uncertainty and are able to make decisions, thus feel more in control. Managers with lower LOC would have a short term orientation (low LTO) since a mid-level manager makes more operational decisions as opposed to long term, strategic decisions.

\section{Performance and Cultural Values}

Given that there is a relationship between personality and job performance, and since culture and personality interact (Hofstede, 2001), it can be speculated that relationships between Hofstede's cultural values and job performance could be detected. In a high power distance (PDI) society the superiors make the decisions, there is a less consultative work environment, so that the power is not distributed equally (Hofstede, 1980, 2001) and subordinates expect an autocratic management style (Hofstede, 1980, 1984). In an international study of mid-level manufacturing managers, Leach-López et al. (2007) found that mid-level managers prefer a more consultative decision making process. Thus, an inverse relationship between PDI and job performance (PER) is expected, i.e. respondents with low PDI will report higher PER.

Uncertainty avoidance is related to the acceptance of an unknown future. Managers with low uncertainty avoidance (UAI) dislike formal rules and are willing to live day to day (Hofstede, 1980, 2001) while high UAI managers would tolerate behaviors and opinions that are different from their own (Flynn \& Saladin, 2006). 
Managers in a high UAI culture are less reactive, less flexible (Wacker \& Sprague, 1998). Managers must be reactive in order to respond to the every day challenges, thus we expect an inverse relationship between UAI and PER so that respondents with low UAI will report higher PER.

An individualistic manager would score high in the Individualism (IDV) construct. Respondents high in the IDV construct would tend to act according to their own interests (Hofstede, 1983a, 1983b) and would value individual success (Flynn $\&$ Saladin, 2006). Collectivism, by contrast, takes satisfaction in a job well recognized. These managers would have more pressure to conform to their in-group and strive to preserve face and avoid shame (Hofstede, 1980, 2001). A direct relationship between IDV and PER is expected so that respondents high in IDV should report higher PER.

Respondents high in the masculinity (MAS) construct (versus a feminism slant) would value high earnings, advancement and challenging work. With a high MAS outlook, an ideal job provides opportunities for recognition, advancement and challenge (Hofstede, 1980, 2001) so that a direct relationship between MAS and PER can be expected, that is, the higher MAS managers should report higher PER. The labels in this cultural classification are used as presented by Hofstede (1980, 2001) and are not meant to be disparaging in any way, nor are they meant to represent the gender of the respondent.

The long-term to short-term orientation dimension is based on teachings similar to those of Confucius. The concepts advocated by Confucius can be found at both ends of this dimension. This cultural value opposes long-term to short-term aspects of Confucian thinking: persistence and thrift compared to personal stability and respect for tradition. Given the duality of this cultural value, it is difficult to determine a priori an expected relationship between LTO and PER.

\section{Moderating Effect of Culture}

Given that there are expected relationships between personality and cultural values and between cultural values and job performance, one would expect to detect a moderating effect of culture on the personality/performance (LOC-PER) relationship. The analysis described below was undertaken to determine which, if any, of the five cultural values moderates, or does not moderate, this relationship. 


\section{Methodology}

\section{Variables and Measures}

Job performance (PER) was measured with an eight-dimension scale developed by Mahoney, Jerdee and Carroll (1963). The Mahoney et al. scale measures eight performance dimensions: planning, investigating, coordinating, evaluating, supervising, staffing, negotiating, and representing. This scale has been widely used in participative budgeting research (e.g., Brownell, 1982, 1983; Brownell \& Hirst, 1986; Brownell \& McInnes, 1986; Frucot \& Shearon, 1991; Leach-López et al., 2007, 2008; Tsui, 2001). Budgets and budget participation are commonly used as management control systems, as well as other accounting measurements such as variance analysis. Job performance was operationalized with the Mahoney et al. scale because it incorporates questions related to accounting measurements and to budgets and variance analysis. Self-reported performance has also been used in other recent studies. Nouri and Parker (1998) employ a self-reported measure of performance adapted from Govindarajan and Gupta (1985) and Shields, Deng and Kato (2000) developed their own self-reported measure of performance. Please see Bommer, Johnson, Rich, Podsakoff and Mackenzie (1995) for a complete discussion of the implications of self-reported performance measures. More recently, Avey, Reichard, Luthans and Mhatre (2011) found no major differences between self reported performance measures and other types of performance measures.

The locus of control personality variable (LOC) was measured with a refined version of the additive scale developed by Rotter (1966). The refined scale includes filler items to disguise the purpose of the test.

The cultural dimensions scores for power distance (PDI), uncertainty avoidance (UAI), individualism (IDV), masculinity (MAS), and long term orientation (LTO) were calculated using Hofstede's VSM 94 (Hofstede, 1994). The respondents were also asked to indicate their gender, age, education, and length of employment in the firm and in their current position.

\section{Data}

Sample. A survey instrument was used to collect the data for this study. The questionnaire was prepared in English and translated to Chinese, Korean, and Spanish. Each mid-level manager completed the survey written in their native language: Chinese, Korean, Spanish, or English. The questionnaires were translated using the method suggested by Hui and Triandis (1985) and by Hui and Yee (1999). First, two individuals highly proficient in English and one of the other languages translated 
from the English version of the questionnaire into Chinese, Korean, or Spanish. The translations were compared and a third bilingual person reviewed the translations. Minor adjustments were made at each step as needed.

Different methods of data collection were employed due to logistical differences within the four countries included in the sample. All of the surveys were completed in a written format. The US sample included emailing the survey instruments to the HR managers. The HR managers forwarded the email to functional managers. The managers who received the forwarded email were instructed to return their completed surveys as email attachments directly to the author. The Mexican samples were all hand delivered to the HR manager and hand collected directly from the managers who decided to complete the survey. The process had to be face to face due to the unreliability of the Mexican postal system. The HR manager of each South Korean firm sampled was contacted and surveys were delivered and returned by mail. The Chinese surveys were answered at one plant located in Hong Kong with the HR manager's permission; they were also hand delivered and hand collected.

The firms in the US were selected by geographic location. They were all located in the southeast US. A directory search yielded the names of manufacturing firms. The firms used were the ones with helpful HR managers. The Mexican firms contacted were registered as maquiladoras in the Interior Department website. The South Korean firms met the criteria of being a US controlled firm. Again, as in the US, the South Korean firms included in this study had helpful managers. Only one Chinese firm was contacted due to limited available contacts in that country.

The full sample consists of mid-level functional managers working in manufacturing firms. The US sample consists of US managers working for US firms in the US. The other subsamples (Mexican, Korean, and Chinese) include foreign managers working for US controlled companies located in Mexico, South Korea, and Hong Kong respectively. The Mexican managers are employed by US controlled maquiladoras located in Mexico. Each of the Korean managers is employed by a different US controlled joint venture firm, while the Chinese managers all work for a single US controlled joint venture firm.

For the US sample, 30 firms located in Southeast United States were contacted and responses were received from 16 firms for a response rate of 53\%. For the Mexican sample, 88 maquiladoras were contacted and 49 firms participated for a response rate of $56 \%$. For the Korean sample, a manager in each of 55 firms was contacted to obtain an oral agreement to participate in this study, 52 responses were obtained for a $94 \%$ response rate. For the Chinese sample, our intent was to obtain a minimum of 50 responses to allow for the minimum sample size of 20 suggested by 
Hofstede (1994). The sample used in this study includes 265 responses: 54 from the US, 90 from Mexico, 71 from South Korea, and 50 from China.

The data gathering had to be conducted according to the limitations placed by the various managerial styles in the four countries and by accessibility to willing respondents. All of the responses were obtained within a two to three week time period. Analyses of the data were conducted to examine whether any non-response biases were present. Tests were conducted to rule-out any potential non-response bias by comparing early to late responders on all study variables and demographics. No significant differences were found between early and late respondents across the study variables.

Common method variance. This study addressed common method variance (CMV) using both ex ante design and ex post analysis. Please see Chang, Witteloostuijn, and Eden (2009) for an excellent explanation of this problem and suggestions to test and handle this concern. The variables used measure the survey respondent's perceptions; therefore, a second source to measure the dependent variable (job performance) was not possible. However, several procedural remedies were incorporated in the questionnaire design. Following standard survey practice, the respondents were assured of anonymity and confidentiality. Respondents were also told that the survey's main purpose was to obtain their honest opinions and perceptions. The survey also used different scale endpoints and formats to "reduce method biases caused by commonalities in scale endpoints and anchor effects" (Chang et al., 2009, p. 3).

The instrument for each variable varied as follows. LOC had 29 questions with possible answers of A/B per question, with 5 filler questions included. PER consisted of 8 questions with ranked answers from 1 to 9 anchored on below average to above average performance. The VSM 94 (Hofstede, 1994) was composed of 20 questions with a Likert type scale ranging from 1 to 5 and anchored on stronglyagree and strongly-disagree. Given this variations and the length of the questionnaire, it would be difficult for the respondents to "cognitively 'create' the correlations needed to produce a CMV-biased pattern of responses" (Murray, Kotabe, \& Zhou, 2005, as reported by Chang et al., 2009, p. 3). To further confirm absence of CMV, the marker-variable technique first proposed by Lindell and Whitney (2001) as discussed by Malhotra, Patil, \& Kim (2007) was used. The CMV discounted correlations and the observed correlations were not statistically different which confirms the finding using Harman's single factor test. Hence, it can be reported that there is no significant evidence of CMV in this study. 


\section{Data Analysis and Results}

Table 1 shows the means and possible range of the variables under study of the captured demographics. It also includes a correlation matrix using Pearson bivariate correlation coefficients for two-tailed relationships of key variables included in this study.

A comparison of the means with the possible ranges provides a profile of the average respondent. The average manager reports a job performance that falls slightly above the third quartile in the possible range. On average, the respondents have an internal personality with low power distance (PDI), high individualism (IDV) and high masculinity (MAS) and rank in the middle for uncertainty avoidance (UAI) and long term orientation (LTO). The average respondent has been with the same firm 10 years and in their current position for 5 years. He or she has attended college and is between 35 and 39 years old. No significant difference in the education level of the respondents in the four countries was detected (School).

The significant relationships found in Table 1 show the expected relationship between job performance (PER) and Locus of Control (LOC) at a high significance level $(\mathrm{p}<0.000)$ and with the expected sign. This result mirrors prior research in that internals report higher job performance. Uncertainty avoidance (UAI) and individualism (IDV) were found to be correlated with job performance $(p<0.05)$. An inverse relationship with UAI was detected, as expected, which indicates that the respondents are able to make decisions and take risks which improves performance. Unexpectedly, a direct relationship between PER and IDV was found. This last result seems to indicate that group effort might generate better performance as opposed to individual efforts. Masculinity was the lone significant relationship detected with locus of control and with the expected inverse relationship. This finding indicates that success is valued by those with internal personalities. 
Table 1

\section{Descriptive Statistics and Correlations}

\begin{tabular}{lcccccccc}
\hline & & & \multicolumn{5}{c}{ Correlations } \\
\cline { 5 - 9 } & $\mathbf{n}$ & Mean & range & PER & sign & LOC & $\begin{array}{c}\text { Expected } \\
\text { sign }\end{array}$ \\
\hline Job Performance (PER) & 265 & 51 & $8-72$ & 1 & & & \\
Locus of Control (LOC) & 264 & 8 & $0-23$ & $-.223^{* *}$ & - & 1 & \\
Power Distance (PDI) & 265 & 27 & $0-100$ & -.019 & - & .109 & + \\
Uncertain Avoidance (UAI) & 265 & 50 & $0-100$ & $-.125^{\star}$ & - & .063 & + \\
Individualism (IDV) & 264 & 74 & $0-100$ & $-.127^{*}$ & + & .045 & - \\
Masculinity (MAS) & 265 & 64 & $0-100$ & .033 & + & $-.270^{\star *}$ & - \\
Long Term Orientation (LTO) & 265 & 49 & $0-100$ & .019 & $?$ & -.051 & + \\
Firm Tenure & 250 & 10 & & & & & \\
Job Tenure & 248 & 5 & & & & & \\
School & 253 & 16 & & & & & \\
Age & 251 & 5 & & & & & \\
Gender & 201 males and 49 females & & & & \\
\hline
\end{tabular}

${ }^{* *}$ correlation is significant at the 0.01 level (2-tailed).

* correlation is significant at the 0.05 level (2-tailed).

The moderating effect of culture on the job performance-locus of control relationship was examined using moderated hierarchical regression as suggested by Aiken and West (1991) and by Barrick, Parks and Mount (2005). In Step 1, the main effect of locus of control and each of the cultural values were controlled by entering them in the initial step of a series of five regressions.

$$
\text { PER }=\text { LOC }+ \text { Cultural value }[\text { Step } 1]
$$

In Step 2, the interaction term of locus of control and each culture value was added. The interaction terms were calculated using centered scores of the independent variables. The variables were centered by subtracting the mean from each score. The results are presented in Table 2.

$$
\text { PER }=\text { LOC }+ \text { Cultural Value }+(\text { LOC } * \text { Cultural Value })[\text { Step 2] }
$$


Table 2

Results of Hierarchical Regression Analysis of Moderating Effect of Culture on the Job Perfomance-Locus of Control Relationship

\begin{tabular}{|c|c|c|c|c|}
\hline \multirow[b]{2}{*}{ Variables } & \multicolumn{2}{|c|}{ Step 1} & \multicolumn{2}{|c|}{ Step 2} \\
\hline & $\beta$ & Std. Error & $\beta$ & Std. Error \\
\hline Constant & $55.86^{\star *}$ & 1.47 & $55.83^{\star *}$ & 1.48 \\
\hline Locus of Control (LOC) & $-0.59^{\star *}$ & .16 & $-0.58^{\star \star}$ & .16 \\
\hline Power Distance (PDI) & 0.01 & .01 & 0.00 & .01 \\
\hline LOC x PDI & & & 0.00 & .00 \\
\hline Model $\mathrm{R}^{2}$ & 0.050 & & 0.050 & \\
\hline Step change in $\mathrm{R}^{2}$ & & & 0.000 & \\
\hline Constant & $56.69^{\star \star}$ & 1.50 & $56.83^{\star \star}$ & 1.49 \\
\hline Locus of Control (LOC) & $-0.56^{\star \star}$ & .16 & $-0.57^{\star \star}$ & .15 \\
\hline Uncertainty Avoidance (UAI) & $-0.02+$ & .01 & $-0.02+$ & .01 \\
\hline LOC x UAI & & & -0.01 & .00 \\
\hline Model R² & 0.062 & & 0.082 & \\
\hline Step change in $R^{2}$ & & & $0.020^{*}$ & \\
\hline Constant & $57.72^{\star \star}$ & 1.69 & $57.62^{\star \star}$ & 1.69 \\
\hline Locus of Control (LOC) & $-0.57^{\star \star}$ & .15 & $-0.55^{\star \star}$ & .15 \\
\hline Individualism (IDV) & $-0.02+$ & .01 & $-0.02+$ & .01 \\
\hline LOC x IDV & & & 0.00 & .00 \\
\hline Model $R^{2}$ & 0.063 & & 0.072 & \\
\hline Step change in $\mathrm{R}^{2}$ & & & 0.009 & \\
\hline Constant & $56.26^{\star *}$ & 1.68 & $56.09^{\star *}$ & 1.69 \\
\hline Locus of Control (LOC) & $-0.59^{\star \star}$ & .16 & $-0.60^{\star *}$ & .16 \\
\hline Masculinity (MAS) & 0.00 & .01 & 0.00 & .01 \\
\hline LOC X MAS & & & 0.00 & .00 \\
\hline Model $\mathrm{R}^{2}$ & 0.050 & & 0.054 & \\
\hline Step change in $\mathrm{R}^{2}$ & & & 0.004 & \\
\hline Constant & $55.68^{\star \star}$ & 2.07 & $55.71^{\star \star}$ & 2.09 \\
\hline Locus of Control (LOC) & $-0.58^{\star \star}$ & .16 & $-0.58^{\star \star}$ & .16 \\
\hline Long Term Orientation (LTO) & 0.00 & .03 & 0.00 & .03 \\
\hline LOC x LTO & & & 0.00 & .01 \\
\hline Model $\mathrm{R}^{2}$ & 0.050 & & 0.050 & \\
\hline Step change in $\mathrm{R}^{2}$ & & & 0.000 & \\
\hline
\end{tabular}

Significance level: ${ }^{* *} p<.01 \quad{ }^{*} p<.05 \quad+p<.10$ 
As reported in Table 2, Locus of Control (LOC) has a significant effect on job performance (PER). The cultural variables Uncertainty Avoidance (UAI) and Individualism (IDV) have a marginal effect (both at $\mathrm{p}<.10$ ) on job performance. UAI is the lone cultural value with a moderating effect on the LOC-PER relationship $(p<.05)$. This moderating effect is very small $(\beta=-0.01)$. No moderating effect of the remaining cultural values was detected on the LOC-PER relationship.

The hierarchical regression model presented in Table 2 was replicated for each country. The results obtained for each country were the same as those obtained for the full model. This indicates that the results are not driven by a particular country due to a larger sample size.

$\mathrm{Ng}$ et al. (2006) concluded that there are five major employees' characteristics that must be modeled when analyzing job outcomes. These characteristics are job level (managers vs. non-managers), job types (manufacturing vs. non-manufacturing), age, job tenure, and gender. In this study, job level and job type were controlled by including only mid-level managers in manufacturing multinational firms. Job tenure and gender were tested and neither was found to be a significant characteristic. Age was found to be significant so that older, more internal, managers report higher job performance.

The results of this study appear very straightforward: culture does not appear to moderate the relationship between the personality variable Locus of Control and self reported Job Performance. The results indicate that the personality of the manager is what drives the manager's job performance. Having high performance employees is critical to the longevity of a firm. The findings indicate that, in order to facilitate job performance across countries, manufacturing multinational corporations can have a level of certainty that they can focus the international human resource function on the individual regardless of the country in which they are operating.

\section{Conclusion, Limitations and Future Research}

The findings indicate that the personality of the manager has a significant relationship with job performance. The cultural values of Uncertainty Avoidance and Individualism have a marginal relationship with job performance. The lone cultural value found to moderate the LOC and job performance relationship was Uncertainty Avoidance. The effect was very small and not highly significant $(\beta=-.01$ and $\mathrm{p}<.05)$. The results indicate that US controlled manufacturing MNCs can confidently address international human resources and design management control systems at the individual level; that is, the personality of the manager is what appears to 
drive the job performance of the manager as opposed to the cultural contingencies. This global integration should increase efficiency to US controlled manufacturing multinational corporations.

This study suffers from some common limitations to this type of research. Despite valiant efforts, the sample size could always be larger. The minimum sample size of 20 recommended by Hofstede (2001) was obtained for each country, though. The unequal sample size from each country might also affect the results. To address this possible limitation, the model was tested using each country's sample and no significantly different results from the overall model were detected. All of the respondents work in firms associated with, or controlled by US firms. Future research is needed to determine whether the respondents have been 'americanized' and whether the findings reported here will hold for foreign firms that are not associated with, or controlled by US multinationals. Another common limitation usually found in this type of research is the use of self reported variables. Established scales were used but each of the scales contains a level of measurement error and it was expected that the respondents would to be truthful and accurate.

Despite these acknowledged limitations, the findings reported contribute to an overlooked area of research as a first line of inquiry. The findings suggest that US controlled manufacturing MNCs should feel free to institute policies addressed to the individual manager's personality without regard to within country or between country cultural differences.

Future research should investigate various management control systems to determine whether the results reported in this study hold. In order to triangulate the results, multinational firms in other countries should be included in the model tested. In addition, non US controlled MNCs and non-manufacturing firms need to be studied. By using non US controlled firms, future research will be able to determine whether an "Americanization" process of managers exists in the US controlled firms, or, is there a self selection process that occurs in multinational corporations? Are certain personalities attracted to US controlled international firms? Or are managers with certain cultural values attracted to international firms? Answers to these questions will help evaluate the generalizability of the findings reported in this study. 


\section{References}

Aiken L. S., \& West, S. G. (1991). Multiple regression: Testing and interpreting interactions, New York: Sage Publications, Inc.

Avey, J. B., Reichard, R. J., Luthans, F., \& Mhatre, K. H. (2011). Meta-analysis of the impact of positive psychological capital on employee attitudes, behaviors, and performance, Human Resource Development Quarterly, 22(2), 127-152.

Barrick, M. R., \& Mount, M. K. (2005). Yes, personality matters: moving on to more important matters, Human Performance, 18(4), 359-372.

Barrick, M. R., Mount, M. K., \& Judge, T. (2001). Personality and performance as the beginning of the new millennium: What do we know and where do we go next?, International Journal of Selection and Assessment, 9, 9-30.

Barrick, M. R., Parks, L., \& Mount, M. K. (2005). Self-monitoring as a moderator of the relationships between personality traits and performance, Personnel Psychology, 58, 745-767.

Blau, G. (1987). Locus of control as a potential moderator of the turnover process, Journal of Occupational Psychology, 60, 21-29.

Bommer, W. H., Johnson, J. L., Rich, G. A., Podsakoff, P. M., \& Mackenzie, S. B. (1995). On the interchangeability of objective and subjective measures of employee performance: A meta-analysis. Personnel Psychology, 48, 587-605.

Brownell, P. (1982). A field study examination of budgetary participation and locus of control. The Accounting Review, 57(October), 766-777.

Brownell, P. (1983). Leadership style, budgetary participation and managerial behavior. Accounting, Organizations and Society, 8(4), 307-321.

Brownell, P., \& Hirst, M. K. (1986). Reliance on accounting information, budgetary participation, and task uncertainty: Tests of a three-way interaction. Journal of Accounting Research (Autumn), 241-249.

Brownell, P., \& McInnes, M. (1986). Budgetary participation, motivation, and managerial performance. The Accounting Review 61 (October), 587-600.

Bruk-Lee, V., Khoury, H. A., Nixon, A. E., Goh, A., \& Spector, P. E. 2009. Replicating and extending past personality/job satisfaction meta-analyses. Human Performance, 22. 156-189. 
Campbell, J. P., McHenry, J. J., \& Wise, L. L. (1990). Modeling job performance in a population of jobs. Personnel Psychology, 43, 313-333.

Campbell, J. P., McCloy, R. A., Oppler, S. H., \& Sager, C. E. (1993). A theory of performance. In N. Schmitt \& W. C. Borman (Eds.), Personnel selection in organizations. San Francisco: Jossey-Bass, 35-70.

Chang, S., Witteloostuijn, A. V., \& Eden, L. (2009). From the editors: Common method variance in international business research. Journal of International Business Studies, 41(2), 1-7.

Flynn, B. B., \& Saladin, B. (2006). Relevance of Baldrige constructs in an international context: A study of national culture. Journal of Operations Management, 24, 583-603.

Frucot, V., \& W. T. Shearon. (1991). Budgetary participation, locus of control, and Mexican managerial performance and job satisfaction. The Accounting Review, 66 (January), 80-98.

Goldberg, L. R. (1993). The structure of phenotypic personality traits. American Psychologist, 48, 26-34.

Govindarajan, V., \& Gupta, A. K. (1985). Linking control systems to business unit strategy: Impact on performance. Accounting, Organizations and Society, 10, 51-66.

Guion, R. M., \& Gottier, R. F. (1965). Validity of personality measures in personnel selection. Personnel Psychology, 18, 135-164.

Harrison, G. L. (1993). Reliance on accounting performance measures in superior evaluative style - The influence of national culture and personality. Accounting, Organizations and Society, 18(4), 319-339.

Hofstede, G. H. (1980). Culture's consequences: International differences in workrelated values. Beverly Hills, CA: Sage Publications.

Hofstede, G. H. (1983a). Dimensions of national cultures in fifty countries and three regions. In J. B. Deregowski, D. Dzuirawiec, \& R. C. Annis, (Eds.), Explications in Cross-cultural Psychology, Swets and Zeitlinger.

Hofstede, G. H. (1983b). The cultural relativity of organizational practices and theories. Journal of International Business Studies, Fall, 75-89. 
Hofstede, G. H. (1984). The cultural relativity of the quality of life concept. Academy of Management Review, 9(3), 389-398.

Hofstede, G. H. (1994). VSM94: Value survey module 1994. Retrieved from stuwww.uvt.nl/ csmeets/ 1st-VSM.html, 9 November 2011.

Hofstede, G. H. (2001). Culture's consequences: Comparing values, behaviors, institutions, and organizations across nations. 2nd edition. Thousand Oaks, CA: Sage Publications, Inc.

Hofstede, G. H., \& Bond, M. H. (1988). The Confucius connection: From cultural roots to economic growth. Organizational Dynamics, 5-21.

Hogan, R. (2005). In defense of personality measurement: New wine for old whiners. Human Performance, 18, 331-341.

Hui, C. H., \& Triandis, H.C. (1985). Measurement in cross-cultural psychology: A review and comparison of strategies. Journal of Cross-Cultural Psychology, 16 (June), 131-152.

Hui, C. H., \& Yee, C. (1999). The impact of psychological collectivism and workgroup atmosphere on Chinese employees' job satisfaction. Applied Psychology: An International Review, 48(2), 175-185.

Judge, T. A., \& Bono, J. E. (2001). Relationship of core self-evaluations traits-self esteem, generalized self-efficacy, locus of control, and emotional stability-with job satisfaction and job performance: A meta-analysis. Journal of Applied Psychology, 86, 80-92.

Kirkman, B. L., Lowe, K. B., \& Gibson, C. B. (2006). A quarter century of Culture's Consequences: a review of empirical research incorporating Hofstede's cultural values framework. Journal of International Business Studies, 37, 285-320.

Lagrosen, S. (2002). Quality management in Europe: A cultural perspective. The TQM Magazine, 14(5), 275-283.

Leach-López, M. A., Stammerjohan, W. W., \& McNair, F. M. (2007). Differences in the role of job relevant information in the budget participation-performance relationship among US and Mexican managers: A question of culture or communication? Journal of Management Accounting Research, 19, 105-136. 
Leach-López, M. A., Stammerjohan, W. W., \& Rigsby, J. T. (2008). An update on budgetary participation, locus of control, and the effects on Mexican managerial performance and job satisfaction. Journal of Applied Business Research, 24(3), 121-134.

Lindell, M. K., \& Whitney, D. J. (2001). Accounting for common method variance in cross-sectional research designs. Journal of Applied Psychology, 86(1), 114121.

Mahoney, T. A., Jerdee, T. H., \& Carroll, S. J. (1963). Development of managerial performance: A research approach. Cincinnati, OH: South-Western Publishing, Co.

Malhotra, N. K., Patil, A., \& Kim, S. S. (2007). Bias breakdown. Marketing Research, 19(1), 24-29.

Murphy, K. R., \& Dzieweczynski, J. L. (2005). Why don't measures of broad dimensions of personality perform better as predictors of job performance? Human Performance, 18(4), 343-357.

Murray, J. Y., Kotabe, M., \& Zhou, J. N. (2005). Strategic alliance-based sourcing and market performance: Evidence from foreign firms operating in China. Journal of International Business Studies, 36(2), 187-208.

Ng, T. W. H., Sorensen, K. L., \& Eby, L. T. (2006). Locus of control at work: A metaanalysis. Journal of Organization Behavior, 27, 1057-1087.

Nouri, H., \& Parker, R. J. (1998). The relationship between budget participation and job performance: The roles of budget adequacy and organizational commitment. Accounting, Organizations and Society, 23, 467-483.

Ozer, M. (2008). Personal and task-related moderators of leader-member exchange among software developers. Journal of Applied Psychology, 93(5), 1174-1182.

Penney, L. M., David, E., \& Witt, L. A. (2011). A review of personality and performance: Identifying boundaries, contingencies, and future research directions. Human Resource Management Review, 21, 297-310.

Perera, M. H. B., \& Mathews, M. R. (1990). The cultural relativity of accounting and international patterns of social accounting. Advances in International Accounting, 3, 215-251. 
Rotter, J. B. (1966). Generalized expectancies for internal versus external control of reinforcement. Psychological Monographs, 80(1), Whole No. 609.

Shields, M. D., Deng, F. J., \& Kato, Y. (2000). The design and effects of control systems: Tests of direct- and indirect-effects models. Accounting, Organizations and Society, 25, 185-202.

Spector, P. E. (1982). Behavior in organizations as a function of employees' locus of control. Psychological Bulletin, 91, 482-497.

Spector, P. E. (2005). Locus of control. Blackwell Encyclopedic Dictionary of Organizational Behavior, 1 .

Tsui, J. S. L. (2001). The impact of culture on the relationship between budgetary participation, management accounting systems, and managerial performance: An analysis of Chinese and western managers. Accounting, Organizations and Society, 36, 125-146.

Wacker, J. G., \& Sprague, L. G. (1998). Forecasting accuracy: comparing the relative effectiveness of practices between seven developed countries. Journal of Operations Management, 16, 271-290.

\section{Biographical Sketch of Author}

Dr. Maria A. Leach-López - Before joining academia, Dr. Leach-López and her husband owned a construction business and had two daughters. She earned a B.A. in accounting from Mississippi University for Women (1987), earned a Master of Professional Accountancy (1988) and a Doctor of Business Administration degree (2002) from Mississippi State University. She is a Certified Public Accountant and a Certified Management Accountant and has taught at Mississippi State University, Jackson State University, and Auburn Montgomery. 